\title{
Electron beam welding of Fe-Mn-Al-Ni shape memory alloy: Microstructure evolution and shape memory response
}

\author{
P. Krooß $\beta^{* *}$, J. Günther*, L. Halbauer ${ }^{\dagger}$, M. Vollmer*, A. Buchwalder ${ }^{\dagger}$, \\ R. Zenker ${ }^{\dagger}$, H. Biermann ${ }^{\dagger}$ and T. Niendorf* \\ *Institut für Werkstofftechnik (Materials Engineering) \\ Universität Kassel, 34125 Kassel, Germany \\ $\dagger$ Institut für Werkstofftechnik (Materials Engineering) \\ Technische Universität Bergakademie Freiberg, 09599 Freiberg, Germany \\ *krooss@uni-kassel.de
}

Received 31 March 2017; Accepted 14 May 2017; Published 3 July 2017

\begin{abstract}
The present study reports on the impact of abnormal grain growth (AGG) on the microstructural evolution following electron beam (EB) welding of Fe-Mn-Al-Ni shape memory alloy (SMA). Polycrystalline sheet-like material was EB-welded and a cyclic heat treatment, studied in previous work, was conducted for inducing AGG and a bamboo-like microstructure, respectively. Optical and electron microscopy were carried out to characterize the prevailing microstructure upon cyclic heat treatment. For characterization of the functional properties following AGG, a load increase test was conducted. The current results clearly show that good shape memory response can be obtained in Fe-Mn-Al-Ni SMA upon EB welding and subsequent post-heat treatment. These results further substantiate the potential use of conventional processing routes for Fe-Mn-Al-Ni SMA.
\end{abstract}

Keywords: EB welding; bamboo structure; phase transformation; grain constraints; pseudoelasticity.

Shape memory alloys (SMAs) attracted a lot of attention during the last decades due to their unique functional material properties. ${ }^{1,2}$ With $\mathrm{Ni}-\mathrm{Ti}$ being the most studied and employed shape memory material, numerous industries like aerospace, energy harvesting and biomedical request these materials as they are well suited for both damping and actuation applications. For example, heavy conventional actuation devices can be substituted. ${ }^{1,2}$ However, processing of Ni-Ti SMAs is rather complex. The competition between economic efficiency and optimal functional material properties necessitates the establishment of cost efficient processing routes. This however remains the major roadblock towards a widespread industrial application of Ni-Ti SMAs. ${ }^{1-6}$

Therefore, alternative shape memory materials like Cu-based ${ }^{7,8}$ and Fe-based ${ }^{4-6,9,10}$ SMAs received a lot of attention due to distinctly lower processing costs compared to conventional Ni-Ti SMAs. Fe-based SMAs are of highest relevance, due to the fact, that alloying elements are cheap and processing routes from steel industry are supposed to be well suited for manufacturing of these alloys. In this regard, studies focusing on $\mathrm{Fe}-\mathrm{Ni}-\mathrm{Co}-\mathrm{Ti}, \quad \mathrm{Fe}-\mathrm{Ni}-\mathrm{Co}-\mathrm{Al}-X$ $(X=\mathrm{Nb}, \mathrm{Ti}, \mathrm{Ta})$ and $\mathrm{Fe}-\mathrm{Mn}-\mathrm{Al}-\mathrm{Ni}-X(X=\mathrm{Ti}, \mathrm{Cr})$ revealed an unprecedented potential in terms of functional properties, i.e. high transformation strains and high bearable stresses in both pseudoelastic and actuation experiments. ${ }^{4-6,10-15}$ However, most Fe-based SMAs suffer rapid cyclic functional degradation, currently hindering industrial utilization. ${ }^{10,15} \mathrm{In}$ single crystalline material, the microstructural mechanisms for cyclic degradation are often related to dislocation formation and concomitant pinning of phase boundaries. In polycrystalline material, grain constraints and related load concentrations often deteriorate functional properties, pronouncedly with increasing material anisotropy. Even grain boundary fracture can occur. ${ }^{10,15,16}$

Recent studies showed that by adjusting the morphology and orientation of grains and grain boundaries with respect to the loading direction functional properties can be significantly improved in SMA systems. ${ }^{16-20}$ In these studies, it was shown that an optimal ratio between grain size and sample size leads to significantly increased shape recovery following pseudoelastic deformation. ${ }^{16-20}$ Omori and coworkers proposed a cyclic heat treatment, leading to abnormal grain growth (AGG) in $\mathrm{Cu}-\mathrm{Al}-\mathrm{Mn}$ and $\mathrm{Fe}-\mathrm{Mn}-\mathrm{Al}-\mathrm{Ni}$ SMAs, resulting in a so-called bamboo-like microstructure, which is characterized by grain boundaries having a predominant alignment perpendicular to the loading

\$Corresponding author.

This is an Open Access article published by World Scientific Publishing Company. It is distributed under the terms of the Creative Commons Attribution 4.0 (CC-BY) License. Further distribution of this work is permitted, provided the original work is properly cited. 
direction. ${ }^{4,20,21}$ These bamboo-like microstructures exhibit distinctly improved functional properties. ${ }^{15,17}$

Concerning an intended industrial application of $\mathrm{Fe}-\mathrm{Mn}-$ Al-Ni SMAs as damping devices embedded in conventional constructions designed from structural materials, in-depth knowledge of the weldability of these alloys is important to effectively implement welding and post-welding treatments, i.e. cyclic heat treatment procedures, into robust industrial manufacturing routes. Therefore, understanding of each single step and corresponding interrelationships on final microstructural features is crucial in order to guarantee proper functional properties in complex constructions.

As a consequence, this study focuses on the weldability of polycrystalline $\mathrm{Fe}-\mathrm{Mn}-\mathrm{Al}-\mathrm{Ni}$ SMAs and addresses the impact of AGG on the microstructure evolution after welding as well as its impact on the functional properties of EB-welded $\mathrm{Fe}-\mathrm{Mn}-\mathrm{Al}-\mathrm{Ni}$ SMA samples.

Using vacuum induction melting, commercially pure polycrystalline $\mathrm{Fe}-\mathrm{Mn}-\mathrm{Al}-\mathrm{Ni}$ ingotss were produced with a nominal chemical composition of $\mathrm{Fe}-34 \% \mathrm{Mn}-14 \% \mathrm{Al}-7.5 \%$ Ni (at.\%) by Stahlzentrum Freiberg e.V. (Freiberg, Germany). After melting, ingots were hot-forged. Bars with a length of $30 \mathrm{~mm}$ and a rectangular cross-section with a thickness of $5 \mathrm{~mm}$ and a width of $22 \mathrm{~mm}$ were cut from the ingots for welding and subsequent heat treatment. The width corresponds to the length of the weldseam.

For welding experiments, an electron beam (EB) universal chamber facility K26-15/80 (pro-beam systems $\mathrm{GmbH}$, Neukirchen, Germany) working at an acceleration voltage of $80 \mathrm{kV}$ was used. Two sheets were butt-welded with a beam current of $6.3 \mathrm{~mA}$ and a travel speed of the EB of $5 \mathrm{~mm} \mathrm{~s}^{-1}$.

Microstructural analyses of the fusion zone and base material were carried out using optical and scanning electron microscopy in order to characterize secondary phase fractions being present after welding. From the welded bar compression samples with dimensions of $3 \mathrm{~mm} \times 3 \mathrm{~mm} \times 6 \mathrm{~mm}$ were electro-discharge machined for mechanical testing. Dimensions of the samples have been chosen in order to avoid geometrical notches. Thus, the size of the samples was limited by the cross-section of the initial bars. The samples were extracted with their loading axis (horizontal direction in Figs. 1 and 2) perpendicular to the welding seam. A scanning electron microscope (SEM) operated at $20 \mathrm{kV}$ equipped with energy dispersive spectroscopy (EDS) and electron-backscatter diffraction (EBSD) units was used for determination of grain morphology and local crystallographic orientations in samples after welding and after the AGG heat treatment procedure, i.e. three heat treatment cycles between $1225^{\circ} \mathrm{C}$ and $900^{\circ} \mathrm{C}$ as developed in previous work ${ }^{22}$ for bulk samples. For mechanical testing, samples were finally heat treated at $200^{\circ} \mathrm{C}$ for $3 \mathrm{~h}$ in order to introduce nano-scaled coherent $\beta$-phase precipitates, crucially needed for thermoelastic martensitic transformation. Details on the heat treatment procedure, detailing the parameters for AGG and precipitation heat treatments, are published elsewhere..$^{22}$

Mechanical testing was done in displacement control using a servo-hydraulic testing rig with an extensometer (gauge length of $12 \mathrm{~mm}$ ) attached to the grips, which are assumed to be absolutely rigid. This setup allows for evaluation of the overall sample behavior, since the gauge section of the extensometer exceeds the length of the sample. An incremental strain test was conducted up to a maximum strain of $3.25 \%$ at room temperature.

Figures 1(a) and 1(b) show optical micrographs within the fusion zone and the base material in the $\mathrm{Fe}-\mathrm{Mn}-\mathrm{Al}-\mathrm{Ni}$ bar after EB welding. The fusion zone appears to be without major defects, such as cracks or pores. Both, the fusion zone center and the base material were analyzed by EDS measurements in order to verify chemical homogeneity (not shown). Using EDS mappings, no chemical inhomogeneity was found in the area probed. Figure 1(b) shows a higher magnification micrograph of the area marked with a white rectangle in Fig. 1(a). From Fig. 1(b), it is apparent, that the fusion zone is characterized by a single phase microstructure. On the right and left side of the fusion zone, i.e. in the base material, a significant fraction of secondary phase is present. It is most likely that this graded microstructure forms mainly due to different local thermal history during EB welding. The temperature gradient from the center of the fusion zone to the base material is supposed to be very high. Thus, locally molten material in the fusion center solidifies rapidly upon relocation of the EB. Due to high cooling rates, a single $\alpha$-phase microstructure evolves in the center. ${ }^{22}$ In a recent work by some of the authors of the current study, it was shown that microstructural properties strongly depend on the quenching rate from $1200^{\circ} \mathrm{C}$ and dwell time at temperatures below, respectively. The quenching sensitivity in $\mathrm{Fe}-\mathrm{Mn}-\mathrm{Al}-\mathrm{Ni}$ SMAs is extremely pronounced. ${ }^{15,22}$ Thus, significant amounts of the secondary $\gamma$-phase evolve in the welding zone in the current work (Fig. 1(b)). As energy is introduced only by the $\mathrm{EB}$, maximum temperatures during welding decrease with increasing distance from the fusion zone center. Concomitantly, local temperature gradients and dwell times are affected significantly.

The EBSD inverse pole figure (IPF) map in Fig. 1(c) reveals grain morphology and local texture of the fusion zone following EB welding. As detailed above, the microstructure consists of a single $\alpha$-phase. The grain morphology turns out to be partly elongated in the upper part of the weldseam, becoming more globular with increasing distance from the top. This grain morphology is typical for keyhole welding and was formed due to different heat transfer conditions between the seam surface and the root run of the weld seam. The corresponding texture plots reveal that the grains in the fusion zone are mainly randomly oriented (texture index plotted is 1.6 

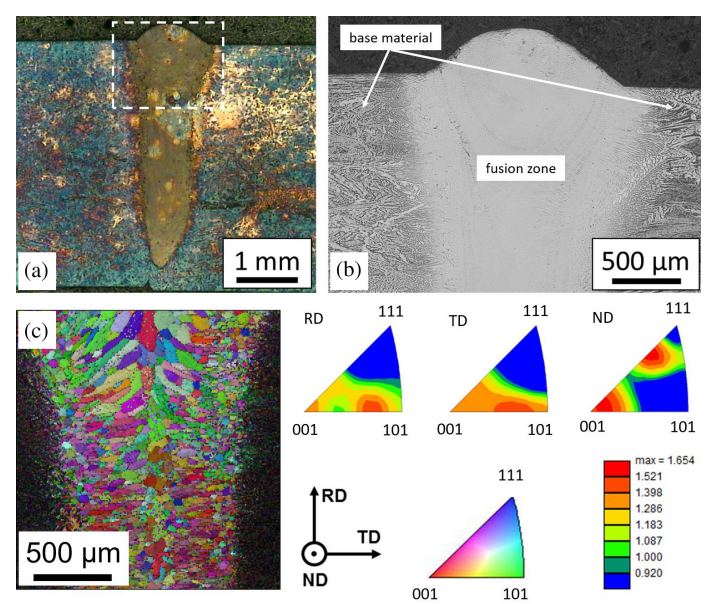

Fig. 1. Microstructure of as-welded Fe-Mn-Al-Ni bars in the fusion zone. (a) optical micrograph of as-welded cross-section, (b) optical micrograph of polished and etched cross-section, (c) EBSD IPF mapping with superimposed image quality and corresponding texture plot of the fusion zone.

only), i.e. preferred texture is hardly observed after EB welding at a beam velocity of $5 \mathrm{~mm} \mathrm{~s}^{-1}$. It is important to note that beam velocity strongly affects grain appearance and texture, respectively. This, however is out of the scope of the current work.

It is well known that functional properties of SMAs are highly anisotropic, i.e. maximum recoverable transformation strains and critical stresses for phase transformation strongly depend on crystallographic orientation. ${ }^{1,2,16,23}$ Therefore, many studies have been conducted in order to understand the role of microstructures on functional properties of SMAs. ${ }^{1,2,15-24}$ In this regard, weakly textured SMAs often show rapid functional and structural degradation due to pronounced grain constraints between favored and non-favored grains in terms of transformability. ${ }^{8,16,25,26}$ In particular, due to highly anisotropic material properties, most SMAs suffer from incomplete shape recovery as a result of defect generation at grain boundaries imposed by the grain constraints as well as defect generation at austenite-martensite phase boundaries and at martensite variant boundaries. ${ }^{10,15,16,18,19}$ In numerous studies focusing on the pseudoelastic performance of a broad variety of SMAs, it was found that microstructural appearance, i.e. grain morphology, texture and grain boundary alignment are of utmost importance for superior functional properties. ${ }^{10,15,16,18,19}$ Vollmer et al. showed that in randomly textured Co-Ni-Ga following multi-axial forging functional properties fully disappeared, whereas bamboo-like microstructures led to superior pseudo-elastic properties. ${ }^{16}$ The main reason for this was found to be related to cracking of grain boundaries oriented parallel to the loading direction (under compressive loading) due to the above-mentioned grain constraints. Thus, grain boundary design with respect to the loading direction and texture control are crucial in highly anisotropic SMAs. Hence, it is most probable that the microstructure of the fusion zone, shown in Fig. 1(c), is characterized

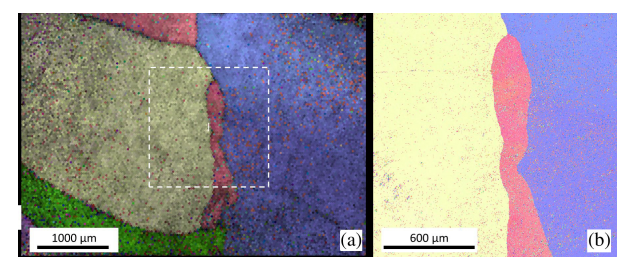

Fig. 2. Microstructure of EB-welded Fe-Mn-Al-Ni compression sample in the fusion zone and base material after AGG. (a) EBSD IPF overview image with superimposed image quality. (b) EBSD IPF map at higher magnification within the fusion zone center marked by the white square in (a). Clearly, no substructures or secondary phases are present.

by poor functionality, as grain constraints linked thereto will lead to functional degradation.

In order to investigate the microstructural evolution upon post-welding heat treatment as well as mechanical properties thereafter, an AGG-heat treatment applying three cycles was conducted. Figure 2(a) shows an IPF map with superimposed image quality of both the fusion zone and the base material after the AGG procedure. Figure 2(b) shows a higher magnification micrograph of the area marked with a white square in Fig. 2(a) in the middle of the former fusion zone center. Figures 2(a) and 2(b) unequivocally reveal that microstructure changed significantly following AGG and subsequent water quenching. AGG led to the disappearance of the aswelded, fine columnar grained microstructure as well as the second phase being present in the base material. Instead, a single-phase coarse grained, bamboo-like microstructure evolved. Thus, the post-welding treatment leads to the disappearance of the as-welded microstructures, which are, again, supposed to be detrimental for functional properties as discussed in previous paragraphs.

In order to gain deeper insights into the locally prevailing conditions, Vickers microhardness measurements were conducted before and after AGG. Figure 3 shows the results of the hardness measurements for the "as-welded" (Fig. 3(a)) and "AGG-heat treated" (Fig. 3(b)) conditions, respectively. The hardness measurements correlate very well with the findings from the EBSD analyses shown in Figs. 1 and 2. The base material $(x=0 \mathrm{~mm}$ to $1.5 \mathrm{~mm}$ and $x=3.5 \mathrm{~mm}$ to $5 \mathrm{~mm}$ ) shows significantly lower hardness values compared to the center of the fusion zone ( $x=1.5 \mathrm{~mm}$ to $3.5 \mathrm{~mm})$ in the aswelded condition (Fig. 3(a)). Figure 3(b) shows the hardness values for the microstructure after AGG-heat treatment. It is obvious that hardness increased distinctly within the base material, whereas the values within the fusion zone decreased (Fig. 3(b)). Comparing the distribution of hardness values as depicted in Figs. 3(a) and 3(b) with micrographs shown in Figs. 1 and 2, it becomes obvious that the lower hardness values in the base material result from the prevailing twophase $\alpha-\gamma$ microstructure. It is well known that the FCC $\gamma$-phase within the BCC $\alpha$-phase leads to an increase in ductility. ${ }^{22}$ Consequently, the single $\alpha$-phase microstructure within the fusion zone center 


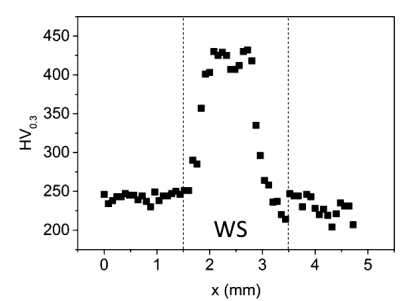

(a)

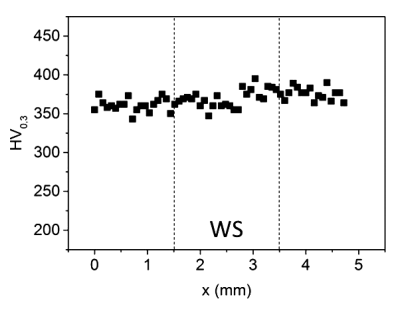

(b)
Fig. 3. Hardness measurements of different sample conditions. (a) aswelded (cf. Fig. 1) and (b) AGG-heat treated (solutionized state, cf. Fig. 2). WS: weld seam.

features considerably higher hardness values compared to the $\alpha-\gamma$ two-phase regions in the base material (Fig. 3(a)). Following AGG and subsequent quenching, the two-phase $\alpha-\gamma$ microstructure in the base material disappeared and hardness increased considerably, due to the formation of a single $\alpha$-phase microstructure (cf. Figs. 2 and 3(b)). Note that the hardness in the previous fusion zone after AGG is somehow lower than in the fusion zone prior to AGG, indicating further changes in microstructure. EDS measurements revealed no significant change in chemical composition. However, it can be assumed that a small fraction of $\beta$-phase particles precipitated imposed by intrinsic heat treatment directly upon EB welding, leading to an increase in hardness in the as-welded condition. A recent study revealed that short-time heat treatment, i.e. $15 \mathrm{~min}$ at $200^{\circ} \mathrm{C}$, already led to the formation of a large fraction of $\beta$-phase particles. ${ }^{5}$ However, the inherent processing conditions leading to the evolution of $\beta$-phase particles imposed by EB welding need to be addressed in more detail in future studies. After solution annealing and water quenching (from $1225^{\circ} \mathrm{C}$ to $80^{\circ} \mathrm{C}$ according to Ref. 22 ), the $\beta$-phase particles are assumed to disappear and the $\alpha$-single phase microstructure evolves, characterized by slightly lower hardness.

Referring to the discussion in the previous paragraphs, the microstructure after AGG, i.e. the coarse grained, $\alpha$-single phase and bamboo-like microstructure satisfies all requirements for good functional properties. Following a precipitation heat treatment at $200^{\circ} \mathrm{C}$ for $3 \mathrm{~h}$ in order to induce finely dispersed $\beta$-particles, ${ }^{4,5,15,2,27}$ a pseudoelastic load increase test was conducted for verification of the aforementioned assumptions. Figure 4 shows the pseudo-elastic stress-strain response of the

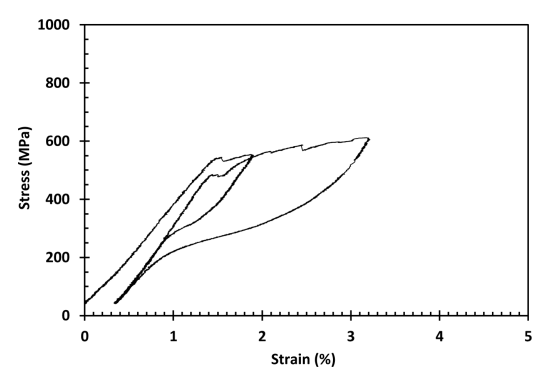

Fig. 4. Stress-strain response of EB-welded Fe-Mn-Al-Ni following AGG and subsequent aging treatment. bamboo-like microstructure after AGG (Fig. 2). Despite some irrecoverable strain of about $0.3 \%$ in the first cycle, the recovery ratio, i.e. the relation of the recoverable strain and the applied strain, is about $91 \%$ in the second cycle up to a maximum strain of $3.25 \%$. Thus, the microstructure of the EB-welded Fe-MnAl-Ni following AGG has been proven to be well suited for good functional material response. In future studies, the impact of different welding conditions on the microstructural evolution and their impact on cyclic functional properties will be addressed.

In conclusion, the EB welding technology is shown to be well suited for joining Fe-Mn-Al-Ni SMAs. Since polycrystalline, weakly textured microstructures are known to be detrimental to good functional properties, the utilization of a post-welding heat treatment, however, has to be considered. Cyclic heat treatment stimulating AGG proved to be an efficient means to design bamboo-like microstructures in EB-welded Fe-Mn-Al-Ni SMAs. The post-treated sample showed good functional material properties.

\section{Acknowledgments}

Financial support by Deutsche Forschungsgemeinschaft (DFG) within the Emmy Noether-program (Contract No. NI1327/7-1) is gratefully acknowledged.

\section{References}

1. K. Otsuka and C. M. Wayman (eds.), Shape Memory Materials (Cambridge University Press, Cambridge, 1999).

2. D Lagoudas (ed.), Shape Memory Alloys - Modeling and Engineering Applications (Springer, New York, 2008).

3. N. B. Morgan, Mater. Sci. Eng. A 378, 16 (2004).

4. T. Omori et al., Science 333, 68 (2011).

5. L. W. Tseng et al., Acta Mater. 97, 234 (2015).

6. Y. Tanaka et al., Science 327, 1488 (2010).

7. R. Dasgupta, J. Mater. Res. 29, 1681 (2014).

8. J. Liu, H. Huang and J. Xie, Mater. Des. 85, 211 (2015).

9. J. Ma et al., Acta. Mater. 60, 2186 (2012).

10. P. Krooß et al., Acta Mater. 79, 126 (2014).

11. T. Maki, S. Furutani and I. Tamura, ISIJ Int. 29, 438 (1989).

12. H. Sehitoglu et al., Scr. Mater. 44, 779 (2001).

13. D. Lee et al., J. Alloys Compds. 617, 120 (2014).

14. Y. I. Chumlyakov et al., Tech. Phys. Lett. 40, 747 (2014).

15. M. Vollmer et al., Scr. Mater. 114, 156 (2016).

16. M. Vollmer et al., J. Alloys Compd. 633, 288 (2015).

17. T. Omori et al., APL Mater. 1, 032103 (2013).

18. S. M. Ueland et al., Adv. Funct. Mater. 22, 2094 (2012).

19. S. M. Ueland and C. A. Schuh, Acta Mater. 60, 282 (2012).

20. T. Omori, Mater. Des. 101, 263 (2016).

21. T. Omori et al., Science 341, 1500 (2013).

22. M. Vollmer et al., Scr. Mater. 108, 23 (2015).

23. H. Sehitoglu et al., Acta. Mater. 48, 3311 (2000).

24. G. Eggeler et al., Mater. Sci. Eng. A 378, 24 (2004).

25. J. Liu, H. Huang and J. Xie, Mater. Des. 85, 427 (2014).

26. R. D. Dar, H. Yan and Y. Chen, Scr. Mater. 115, 113 (2016).

27. T. Niendorf et al., Metall. Mater. Trans A 74, 2569 (2016). 